\title{
Metabarkodlama yaklaşımıyla Tuz Gölü, Türkiye mikroorganizmalarının belirlenmesi için bir pilot çalışma
}

\author{
Hasan Ünal ${ }^{1}$, Sibel Küçükyıldırım ${ }^{1 *}$ \\ ${ }^{1}$ Hacettepe Üniversitesi, Biyoloji Bölümü Beytepe, Ankara 06800 Türkiye (ORCID: 0000-0003-2241-3060; 0000-0003-3492-0326)
}

(Illk Geliş Tarihi 30 Ocak 2020 ve Kabul Tarihi 7 Haziran 2020)

(DOI: 10.31590 /ejosat.682557)

ATIF/REFERENCE: Ünal, H. \& Küçükyıldırım, S. (2020). Metabarkodlama yaklaşımıyla Tuz Gölü, Türkiye mikroorganizmalarının belirlenmesi için bir pilot çalışma. Avrupa Bilim ve Teknoloji Dergisi, (19), 366-374.

\section{$\ddot{\mathbf{O} z}$}

Mikroskopi ve kültür tekniklerine dayanan geleneksel mikrobiyal yöntemler oldukça etkili olmalarına rağmen, çevresel örneklerde bulunan mikrobiyal türlerin yüksek çeşitliliğini tanımlamakta zaman zaman yetersiz kalmaktadır. Geçtiğimiz son yirmi yılda, moleküler teknikler önemli düzeyde gelişmiştir ve genomik yaklaşımlar mikroorganizmaların dağılımını daha kapsamlı ve nicel olarak tanımlamak için kullanılmaktadır. Bu pilot çalışmada, Tuz Gölü'nde bulunan prokaryotik ve ökaryotik mikroorganizmaların çeşitliliği metabarkodlama yaklaşımıyla araştırılmıştır. 16S / 18S rDNA dizilemesi sonuçlarına göre, örneklerde ortalama 29 arkeal, 23 bakteriyel ve 61 ökaryotik OTU belirlenmiştir ve prokaryotik OTU`ların oranı \%65,3'tür. Tüm örneklerde, en çok belirlenen arkeal OTU Euryarchaeota şubesinden Haloquadratum walsbyi`e aittir ve en yaygın bakteriyel OTU ’ar ise Salinibacter cinsinin üyelerine aittir. 18S rDNA sekanslama sonuçlarına göre, en çok gözlenen ökaryotik OTU, Dunaliella salina`dır. Bu çalışmada, in vitro kültürü yapılamayan birçok prokaryotik ve ökaryotik OTU tespit edilmiş ve veritabanlarındaki $16 \mathrm{~S}$ rDNA sekanslarına \% 97'den az benzerliği (\% 92) olan bir OTU belirlenmiştir. Elde edilen sonuçlar, Tuz Gölü'ndeki mikrobiyal toplulukların yapısının ve bileşiminin aydınlatılmasina katkıda bulunma potansiyeline sahiptir.

Anahtar Kelimeler: Biyoçeşitlilik, Tuz Gölü, Halofil, 16S rDNA, 18S rDNA, Mikroorganizma

\section{A pilot study for determining microorganisms in Lake Tuz, Turkey by metabarcoding approach}

\begin{abstract}
Although traditional microbial methods based on microscopy and culture techniques are highly effective, they are sometimes inadequate to identify the high diversity of microbial species found in environmental samples. In the past two decades, molecular techniques have improved significantly, and genomic approaches have been used to provide a more comprehensive and quantitative description of the distribution of microorganisms. In this pilot study, prokaryotic and eukaryotic microbial diversity of the samples from Lake Tuz was investigated by metabarcoding approach. According to the 16S / 18S rDNA sequencing results, an average of 29 Archaea, 23 Bacteria and 61 Eukaryotic OTUs were determined in the samples and the ratio of prokaryotic OTUs was 65.3\%. In all examples, the most detected archaeal OTU belongs to Haloquadratum walsbyi from the Euryarchaeota branch, and the most common bacterial OTUs belong to the members of the genus Salinibacter. In accordance with the $18 \mathrm{~S}$ rDNA sequencing results, the most abundant eukaryotic OTU is Dunaliella salina. In this study, many prokaryotic and eukaryotic OTUs that could not be cultured in vitro were detected and an OTU with less than $97 \%$ similarity $(\leq 92 \%)$ to $16 \mathrm{~S}$ rDNA sequences in their databases was determined. The results obtained have the potential to contribute to the clarification of the structure and composition of microbial communities in Lake Tuz.
\end{abstract}

Keywords: Biodiversity, Lake Tuz, Halophile, 16S rDNA, 18S rDNA, Microorganism

\footnotetext{
Sorumlu Yazar: Hacettepe Üniversitesi, Biyoloji Bölümü Beytepe, Ankara 06800 Türkiye, ORCID: 0000-0003-2241-3060, sibelkucukyildirim@gmail.com
} 


\section{Giriş}

Ekosistem kararlılığına ve sürdürülebilirliğine katkıda bulunması nedeniyle biyoçeşitlilik örüntülerini açıklamak ve öngörmek oldukça önemlidir. Geçtiğimiz yüzyıl boyunca gerçekleştirilen biyoçeşitlilik temelli araştırmaların çoğunda sadece bitki ve hayvanlara odaklanılmıştır. Ancak, giderek artan moleküler ve ekolojik kanıtlar, mikroorganizmaların öngörülenden daha yüksek çeşitliliğe sahip ve karmaşık olduğunu göstermiştir (Pace, 1997; Harris ve ark., 2013). Mikroorganizmalar, sayıca üstün olmalarının yanı sıra taksonomik ve metabolik olarak da en yüksek çeşitliliğe sahip gruptur (Pike ve ark., 2018). Günümüzde, az keşfedilmiş ve bazı uç özelliklere sahip ortamlar (yüksek ya da düşük sıcaklık, yüksek ya da düşük pH gibi) başta olmak üzere çeşitli habitatlarda mikrobiyal biyoçeşitlilik çalışmaları gerçekleştirilmiştir.

Dünya genelinde yaygın olarak bulunan yüksek tuzluluğa sahip ortamlar arasında göller, tuzlalar ve göletler, doğal kaynaklar ve bazı topraklar sayılabilir (Oren, 2014). Hipersalin ekosistemlerde yapılan biyoçeşitlilik araştırmalarında çoğunlukla tuzlalar ve göller üzerine yogunlaşılmıştır (Tazi ve ark., 2014; Ventosa ve ark., 2014; Abdallah ve ark., 2016). Bu çalışmalarda, incelenen hipersalin ortamların bakteriler, arkeler, virüsler ve ökaryotlar da dahil olmak üzere tüm taksonomik grupları içerdiği gösterilmiştir (Emerson ve ark., 2012; Emerson ve ark., 2013; Oren, 2014). Bununla birlikte, farklı taksonların dağılımının ve popülasyon büyüklüğ̈̈nün, ortamın tuzluluk özelliğine bağlı olarak değişebileceği rapor edilmiştir, örneğin, \%25'in üzerindeki tuzluluklarda, arkelerin bakterilerden daha baskın olabileceği belirlenmiştir (Simachew ve ark., 2016).

Günümüzde çeşitli çevresel örneklerde tür çeşitliliğini karakterize etmek için sıklıkla amplikon dizileme esasına dayanan metabarkodlama yaklaşımı kullanılmaktadır ve bu yöntemin nadir taksonları belirleyebilme potansiyeline sahip olduğu kabul edilmektedir. Bu yaklaşım ilk olarak mikrobiyal topluluklara (Sogin ve ark., 2006) uygulanmıştır. Daha sonra, mantarlar (Fouts ve ark., 2012), omurgasızlar (Porazinska ve ark., 2010), bitkiler (Hiiesalu ve ark., 2012) ve omurgalılar 1 (Kowalczyk ve ark., 2011; Raye ve ark., 2011; Brown ve ark., 2012) kapsayan çalışmalarda kullanılmıştır. Metabarkodlama yönteminin sahip olduğu yüksek duyarlılık ve özgüllük, özellikle in vitro ortamda üretilemeyen organizmalar konusunda avantaj sağlamaktadır (Fouts ve ark., 2012; Abdelfattah ve ark., 2017; Pavan-Kumar ve ark., 2015). Bu yöntemde, ilgilenilen domeyndeki türler arasında yüksek oranda korunan ancak tür hatta alttür seviyesinde filogenetik ayrım yapmaya olanak sağlayacak değişken bölgelere sahip olduğu bilinen bazı gen bölgelerinden (örneğin bakteriler için 16S rDNA geni, ökaryotlar için 18S rDNA geni ve ITS bölgesi) yararlanılmaktadır (AmaralZettler ve ark., 2009; Caporaso ve ark., 2011; Caporaso ve ark., 2012; Parada ve ark., 2016; Walterse ve ark., 2016) .

$\mathrm{Bu}$ pilot araştırmada örnekleme alanı olarak seçilen Tuz Gölü, çevresindeki flora ve faunasıyla dünyanın en önemli doğal alanlarından biri olarak kabul edilmektedir ve sahip olduğu biyolojik çeşitlilik değerlerinden dolayı Özel Çevre Koruma Bölge si olmasının yanı sıra Önemli Kuş Alanı (ÖKA), Önemli Bitki Alanı (ÖBA) ve Önemli Doğa Alanı (ÖDA) statülerini de taşımaktadır. Ankara'nın $120 \mathrm{~km}$ güneyinde, merkez platoda yer alan Tuz Gölü, 1665 km2 toplam yüzölçümü ile Türkiye'nin en büyük ikinci gölüdür. Kış mevsiminde göl sığdır (1-2 m), yaz aylarında ise kurur ve tuz konsantrasyonu \%33'e ulaşır. Türkiye'de yıllık tuz üretiminin yarısından fazlasına katkıda bulunan Tuz Gölü, thalassohaline özellikte bir iç su kütlesidir (Koday, 1999).

Bu pilot çalışmanın amacı, Tuz Gölü mikrobiyal biyoçeşitliliğinin kültürden bağımsız bir yöntem olan metabarkodlama yaklaşımı kullanılarak belirlenmesidir. Literatürde, Tuz Gölü mikrobiyal biyoçeşitliliğini inceleyen çalışmalar mevcuttur (Birbir ve Sesal, 2003; Mutlu, 2006). Ancak, genellikle prokaryotik organizmalara odaklanılmış olan bu çalışmalarda yakın zamana kadar mikroskopi ve kültür tekniklerine dayanan yöntemler tercih edilmiştir. Mutlu ve arkadaşlarının (2008) kültürden bağımsız bir yöntem kullandıkları araştırmalarında ise, Tuz Gölü'nde yaygın olarak bulunan arke ve bakteri domeynlerine ait türler tanımlanmıştır. Ancak literatürde, Tuz Gölü ökaryotik mikroorganizmalarının değerlendirildiği bir çalışma mevcut değildir. Bu nedenle, bu pilot çalışma Tuz Gölü'ndeki prokaryotik ve ökaryotik mikrobiyal toplulukların çeşitliliğinin aydınlatılmasına katkıda bulunma potansiyeline sahiptir.

\section{Materyal ve Metot}

\section{1. Örnekleme ve Fizikokimyasal Analiz}

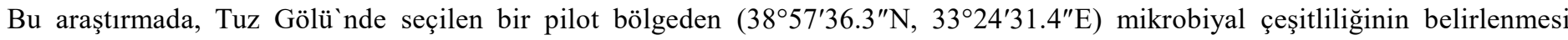
amacıyla, Mart 2018'de, 10 ila $40 \mathrm{~cm}$ derinlikten, beş adet su örneği ( 1 L) aseptik olarak alınmıştır (Şekil 1). Alınan tüm örnekler $4{ }^{\circ} \mathrm{C}^{\prime} \mathrm{de}$ muhafaza edilmiş ve hemen laboratuvara taşınmıştır. Örneklerde fizikokimyasal parametrelerin (toplam tuzluluk, majör anyon ve katyon konsantrasyonları $\left(\mathrm{Na}^{+}, \mathrm{K}^{+}, \mathrm{Ca}^{2+}, \mathrm{Mg}^{2+} \mathrm{Cl}^{-}, \mathrm{CO}_{3}{ }^{2-}, \mathrm{SO}_{4}{ }^{2-}\right.$ ve $\mathrm{NO}_{3}{ }^{-}$ile $\left.\mathrm{pH}\right)$ analizi Hacettepe Üniversitesi Su Kimyası Laboratuvarı tarafindan yapılmıştır. 


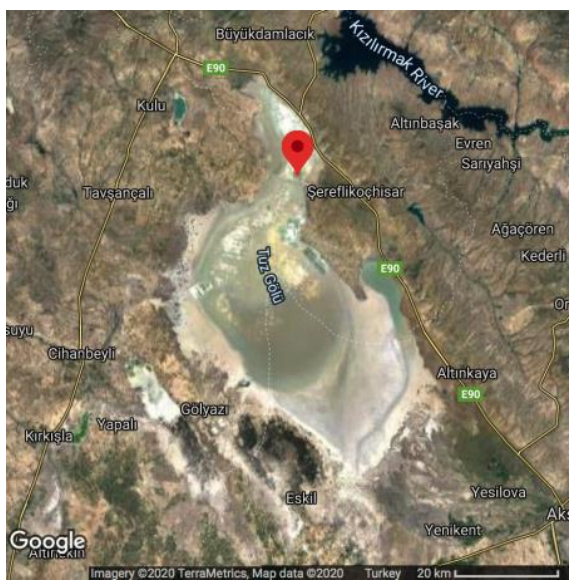

Şekil 1. Tuz Gölü, Türkiye. Örnekleme alanı kırmızı belirteç ile işaretlenmiştir (Uydu görüntüsü: Google/Google Maps (n.d.)).

\subsection{DNA İzolasyonu ve Metabarkodlama}

DNA izolasyonu için, alandan getirilen su örnekleri $(500 \mathrm{ml})$, vakumla filtreden $(0.22$ um filtre membranı) süzülmüştür. Filtre membranları daha sonra kesilerek küçük parçalara bölünmüştür ve ZymoBIOMICS® DNA Miniprep Kiti (Zymo Research, Irvine, CA) kullanılarak üreticinin talimatlarına göre DNA izolasyonu gerçekleştirilmiştir. İzole edilen DNA örnekleri \%1 agaroz jelde kontrol edilmiştir ve DNA miktarı Nanodrop 2000 UV-Vis spektrofotometresi (Thermo Fisher, A.B.D.) kullanılarak belirlenmiştir. DNA örnekleri hizmet alımını gerçekleştiren firmaya teslim edilene kadar $-20{ }^{\circ} \mathrm{C}$ 'de muhafaza edilmiştir.

Örneklerden izole edilen yüksek kalitedeki DNA, dizileme hizmeti için Zymo Research (Irvine, California, A.B.D.)’ye gönderilmiştir. Prokaryotik 16S rDNA geninin V4-V5 değişken bölgelerini hedefleyen özgül primerler (beklenen amplikon büyüklüğü yaklaşık 300-350 bç) (515F (5'-GTGYCAGCMGCCGCGGTAA-3') ve 806R (5'-GGACTACNVGGGTWTCTAAT-3')); ve ökaryotik mikroorganizmaların tespit edilmesi için 18S rDNA geninin V9 değişken bölgesine özgül primerler (beklenen amplikon büyüklüğü yaklaşık 260 bç) (1391F (5'-GTACACACCGCCCGTC-3') ve EukBR (5'-TGATCCTTCTGCAGGTTCACCTAC-3') kullanılmıştır (Amaral-Zettler ve ark., 2009; Caporaso ve ark., 2011; Caporaso ve ark., 2012; Parada ve ark., 2016; Walterse ve ark., 2016). "Earth Microbiome Project" de önerilen protokollere uygun barkod primer seti Illumina MiSeq cihazına adapte edilmiş olarak kullanılmıştır (Caporaso ve ark., 2012). Amplikon kütüphaneleri hazırlandıktan sonra, ürünlerin miktarı, qPCR floresan okumaları ile ölçülmüş ve eşit molaritede birleştirilmiştir. Birleştirilmiş kütüphane, Select-a-Size DNA Clean \& Concentrator TM (Zymo Research, Irvine, CA) kullanılarak saflaştırılmıştır, TapeStation ${ }^{\circledR}$ ve Qubit ${ }^{\circledR}$ cihazları ile nitel ve nicel kontrolleri yapılmıştır. Örnekler firmanın önerdiği protokol izlenerek Illumina MiSeq cihazı ile dizilenmiştir.

\subsection{Verilerin analizi}

Ham veriler Dada2 programı ile işlenerek özgül amplikon dizileri elde edilmiştir ve aynı program kullanılarak kimerik diziler analiz dışı bırakılmıştır (Callahan ve ark., 2016). QIIME v.1.9.1 programındaki UCLUST fonksiyonu 97\%'den daha fazla benzerlik içeren DNA dizi verilerini operasyonel taksonomik birimler (OTU'lar) olarak kümelemek için kullanılmıştır (Caporaso ve ark., 2010; Ramette, 2009). Kimerik OTU'lar, USEARCH algoritması kullanılarak veri setinden çıkarılmıştır (Edgar, 2013). Bir pilot proje olarak tasarlanan bu çalışmada, farklı veri bankalarından elde edilen sonuçların karşılaştırılabilmesi için prokaryotik OTU'ların ilişkili olduğu taksonların belirlenmesinde Greengenes (DeSantis ve ark., 2006) ve Zymo Research veri bankaları kullanılmıştır. Ancak, ökaryotik organizmalar için veri bankalarının halen sınırlı içeriğe sahip olması nedeniyle sadece Zymo Research veri bankası ile karşılaştırma yapılabilmiştir. OTU ların taksonlarla ilişkilendirilmesinde benzerlik alt sınırı olarak \% 70 uygulanmıştır. Alfa çeşitlilik analizleri QIIME v.1.9.1 ile yapılmıştır (Ramette, 2009). 16S and 18S rDNA genlerine ait ham dizileme verileri NCBI veri tabanına PRJNA626417 numarasıyla kaydedilmiştir.

\section{Araştırma Sonuçları ve Tartışma}

\subsection{Fizikokimyasal Analizler}

Örnekleme sırasında ölçülen ortalama sıcaklık $14,2^{\circ} \mathrm{C}$ ve ortalama pH 7,44`dür. Örneklerin fizikokimyasal özellikleri Tablo 1 'de gösterilmektedir. Gölden alınan tuz örneklerinde Sodyum $\left(\mathrm{Na}^{+}\right)$ve Klorür $\left(\mathrm{Cl}^{-}\right)$iyonlarının en yüksek konsantrasyona sahip olduğu belirlenmiştir, ek olarak Magnezyum $\left(\mathrm{Mg}^{2+}\right)$, Potasyum $\left(\mathrm{K}^{+}\right)$, Kalsiyum $\left(\mathrm{Ca}^{2+}\right)$ ve Bikarbonat iyonlarının $\left(\mathrm{HCO}_{3}{ }^{-}\right)$konsantrasyonları da dikkate alındığında, bu kimyasal bileşimin halofilik organizmaları desteklemesi beklenebilir. 
European Journal of Science and Technology

Tablo 1. Tuz Gölü 'nden alınan su örneklerinde belirlenen fizikokimyasal parametreler (iyon konsantrasyonları g/L cinsinden verilmişstir).

\begin{tabular}{cccccccccc}
\hline Örnek No & Renk & $\begin{array}{c}\text { Sıcaklık } \\
\left({ }^{\mathbf{C}} \mathbf{C}\right)\end{array}$ & $\mathbf{p H}$ & $\mathbf{N a}^{+}$ & $\mathbf{K}^{+}$ & $\mathbf{C a}^{\mathbf{2}}$ & $\mathbf{M g}^{\mathbf{+}}$ & $\mathbf{H C O}_{3}{ }^{-}$ & $\mathbf{C l}^{-}$ \\
& Çok açık pembe & & 7,42 & 127.18 & 2.34 & 1.41 & 4.75 & 0.25 & 229.35 \\
1 & Çok açık pembe & 14.22 & 7,42 & 127.83 & 2.27 & 1.30 & 5.11 & 0.23 & 229.97 \\
2 & Çok açı pembe & & 7,48 & 128.18 & 2.36 & 1.32 & 5.73 & 0.28 & 231.27 \\
3 & Çok açık pembe & & 7,46 & 127.54 & 2.33 & 1.37 & 5.64 & 0.15 & 230.99 \\
4 & Çok açık pembe & & 7,43 & 126.74 & 2.12 & 1.29 & 4.91 & 0.21 & 228.93 \\
5 & & & 7,44 & 127.49 & 2.28 & 1.33 & 5.22 & 0.22 & 230.1 \\
\hline
\end{tabular}

\subsection{S rDNA Dizileme}

Bu çalışma kapsamında, Tuz Gölü’nden alınan 5 örnekte prokaryotik mikroorganizmaların çeşitliliği başarılı şekilde karakterize edilmiştir. 16S rDNA dizilime sonucu elde edilen ham okumalara veri kalitesini arttırmak için filtreleme uygulanmıștır, örnek başına ortalama 20980 yüksek kaliteli çift yönlü okuma elde edilmiştir ve bu okumalar arasında, benzersiz dizilerin sayıs1 55 -121 arasında değişmektedir. 16S rDNA dizilemesi başarıyla gerçekleştirilen 5 örnekte, OTU'ların kümelenmesi ve ilgili taksonomik birimlere atanması sırasında sonuçların güvenirliliği arttırmak amacıyla iki farklı veri tabanı (Greengenes ve Zymo Research) kulla nılarak analiz edilmiştir.

OTU'ların Greengenes veri tabanıyla karşılaştıılması sonucunda, örnek başına belirlenen ortalama prokaryotik OTU sayısı 22'dir (örneklerde tanımlanan toplam OTU sayısı 20 ile 47 arasında değişmektedir). Greengenes sonuçlarına göre, örneklerde belirlenen OTU 'ların ortalama \%90,6`sı arke türlerine aittir (örneklerde arke OTU’larının oranı \%82,6 ile 96 arasında değişmektedir). Tüm örneklerde tespit edilen arkeal OTU ların tamamı Euryarchaeota şubesinden Halobacteriaceae ailesine aittir (Şekil 2A ve 2C). En yüksek sıklıkta belirlenen arke OTU'ları sırasıly Halobacterium $(\% 43,8)$, Haloquadratum (\%18), Halorahabdus $(\% 17,8)$ ve Halorubrum $(\% 0,05)$ cinsleriyle ilişkilidir (Şekil 2E). Bakteri filumları arasında Bacteroidetes baskındır, tüm örneklerde ortalama $\% 7,8$ oranında belirlenmiştir, onu sırasıyla Proteobacteria (ortalama \%1,08), Cyanobacteria (ortalama \%0,22), Firmicutes (ortalama $\% 0,12$ ) ve Thermi (ortalama \%0,04) takip etmektedir (Şekil 2A). Tüm örneklerde toplam 38 farklı bakteri OTU'su tanımlanmıştır. Analiz edilen tüm örneklerde bulunan ve en çok rastlanan bakteri OTU'ları sırasıyla Salinibacter $(\% 7)$, Halomonas $(\% 0,3)$, Marinobacter $(\% 0,2)$, Idiomarina $(\% 0,1)$ cinsleriyle ilişkili bulunmuştur (Şekil 2E).

OTU'ların Zymo Research veri tabanıyla karşılaştırılması sonucunda, örnek başına tanımlanan ortalama prokaryotik OTU sayısı 52'dir (örneklerde tanımlanan OTU sayısı 30 ile 86 arasında değişmektedir). Tespit edilen arkeal OTU'lar Euryarchaeota ve Nanohaloarchaeota şubelerine aittir ve örneklerdeki mikrobiyal kompozisyonun ortalama \%90,5 ni oluşturmaktadır (Şekil 2B). En yüksek oranda tespit edilen arkeal OTU Halobacteriaceae ailesinin üyeleriyle ilişkilidir (Şekil 2D). Tüm örneklerde tespit edilen OTU'ların ortalama \%39'u Haloquadratum walsbyi türüne aittir (Şekil 2F). Greengenes veri tabanı karşılaştırma sonuçlarıyla uyumlu olarak, Bacteroidetes baskın bakteriyel filumdur (ortalama \%7,8), onu sirasiyla Proteobacteria (ortalama \%1,08), Cyanobacteria (ortalama \%0,22), Firmicutes (ortalama \%0,12) ve Thermi (ortalama \%0,04) takip etmektedir (Sekil 2B). Tüm örneklerde ortak olarak bulunan bakteriyel OTU Salinibacter cinsiyle ilişkilidir ve ortalama \%7 oranında tespit edilmiştir (Şekil 2F).

Zymo Research veri tabanıyla yapılan karşılaştırma sonucuna göre, bir OTU (4 adet farklı dizi varyantına sahiptir) veri tabanındaki diğer dizilerle \%97'den daha az benzerliğe sahiptir (\%90-92), ve bu OTU en yüksek benzerliği (\%90-92) Halobonum cinsi ile paylaşmaktadır (Şekil 2F). Greengenes veri tabanı sonuçlarına göre ise aynı OTU Halobacteriaceae ailesine atanmıştır fakat herhangi bir cins ya da tür ile ilişkilendirilememiştir. Ek olarak NCBI, SILVA ve RDP veri bankalarıla da karşıllaştırılmıştır ancak \%95'den daha fazla benzerlik gösterdiği bir dizi bulunamamıştır. Literatürde, \%97`den daha az oranda 16S rDNA gen dizisi benzerli ğini paylaşan birimlerin aynı türe ait olmadığına dair kapsamlı kanıtlar mevcuttur (Martinez-Murcia ve Collins, 1990; Collins ve ark., 1991; Amann ve ark., 1992; Fow ve ark., 1992; Martinez-Murcia ve ark., 1992; Tindall ve ark., 2010). Bu nedenle, bahsedilen OTU ile ilişkili dizilerin yeni bir türe ait olma olasılığı dikkate alınarak, ileri analizlerle doğrulanana kadar, NCBI veri tabanında ayrı bir kayıt oluşturulmuştur. 
A

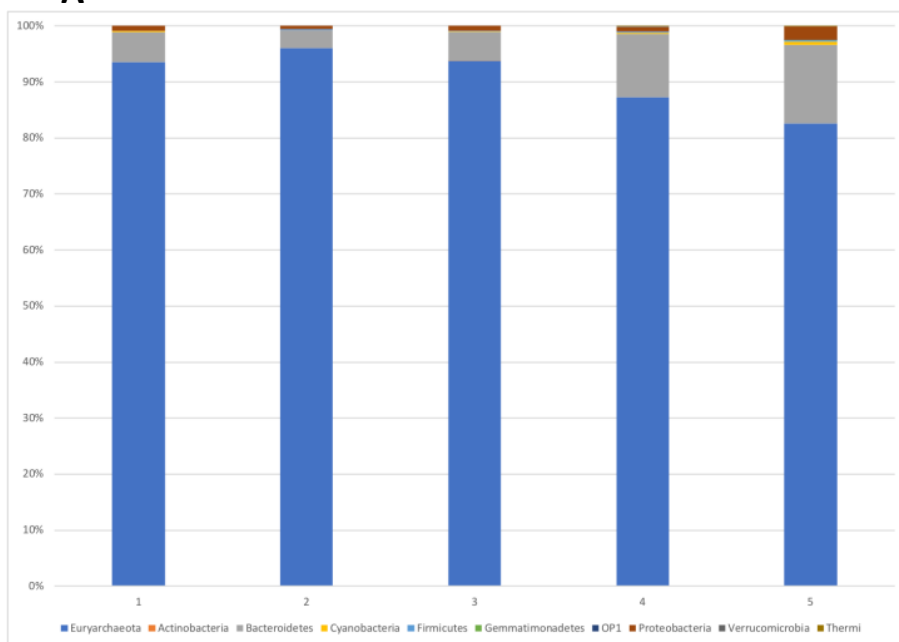

C

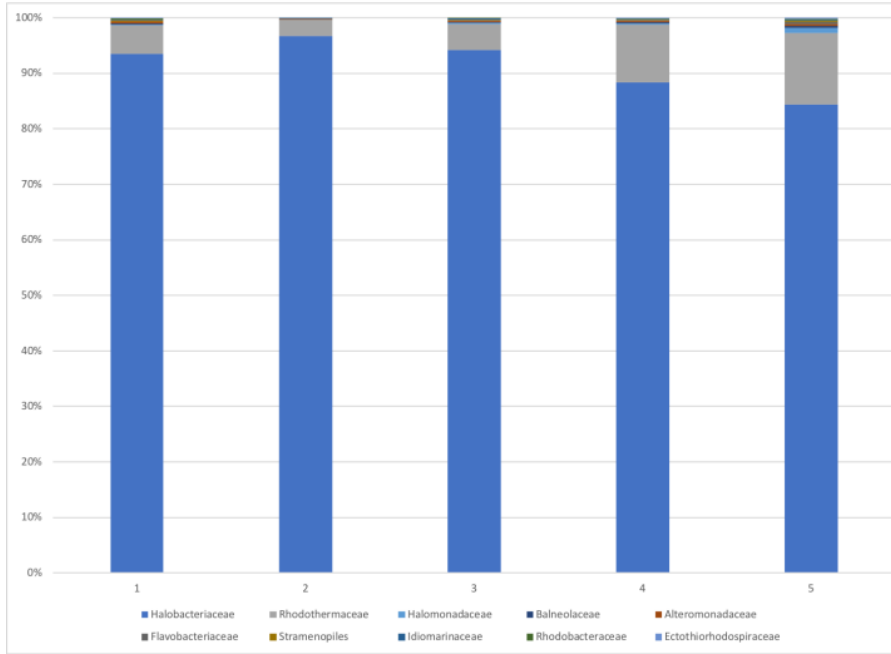

\section{E}

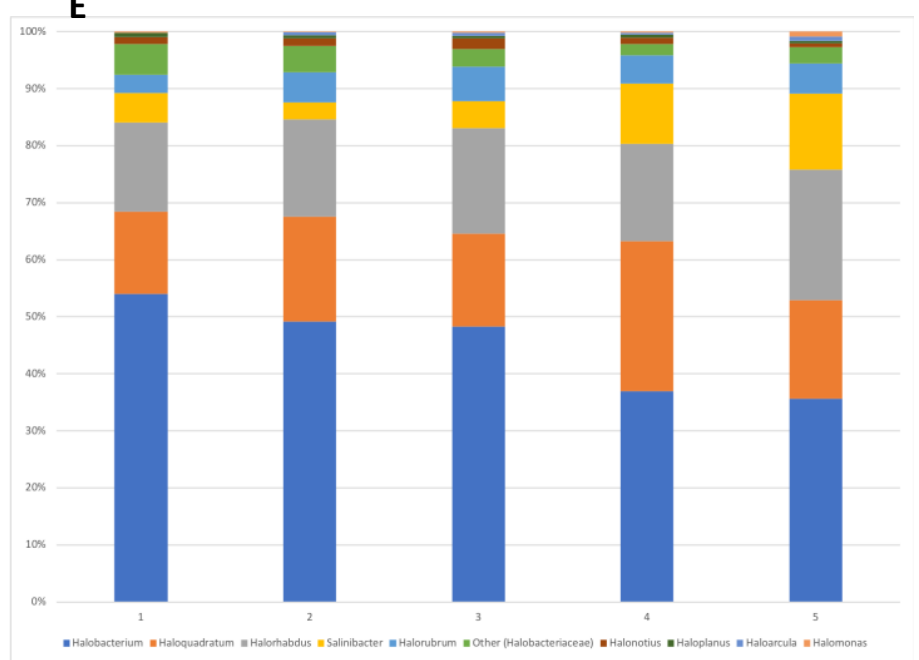

B

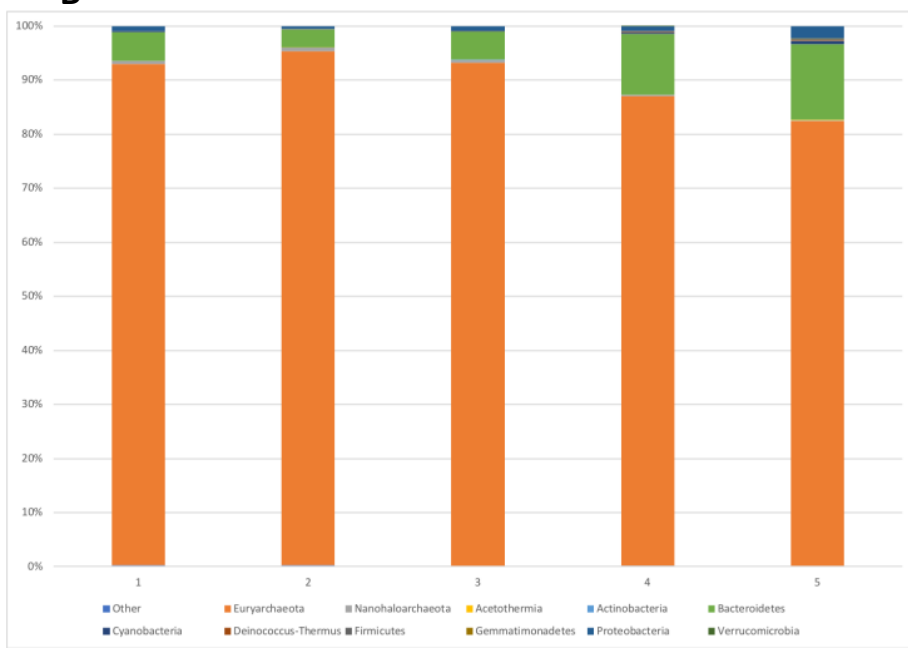

D
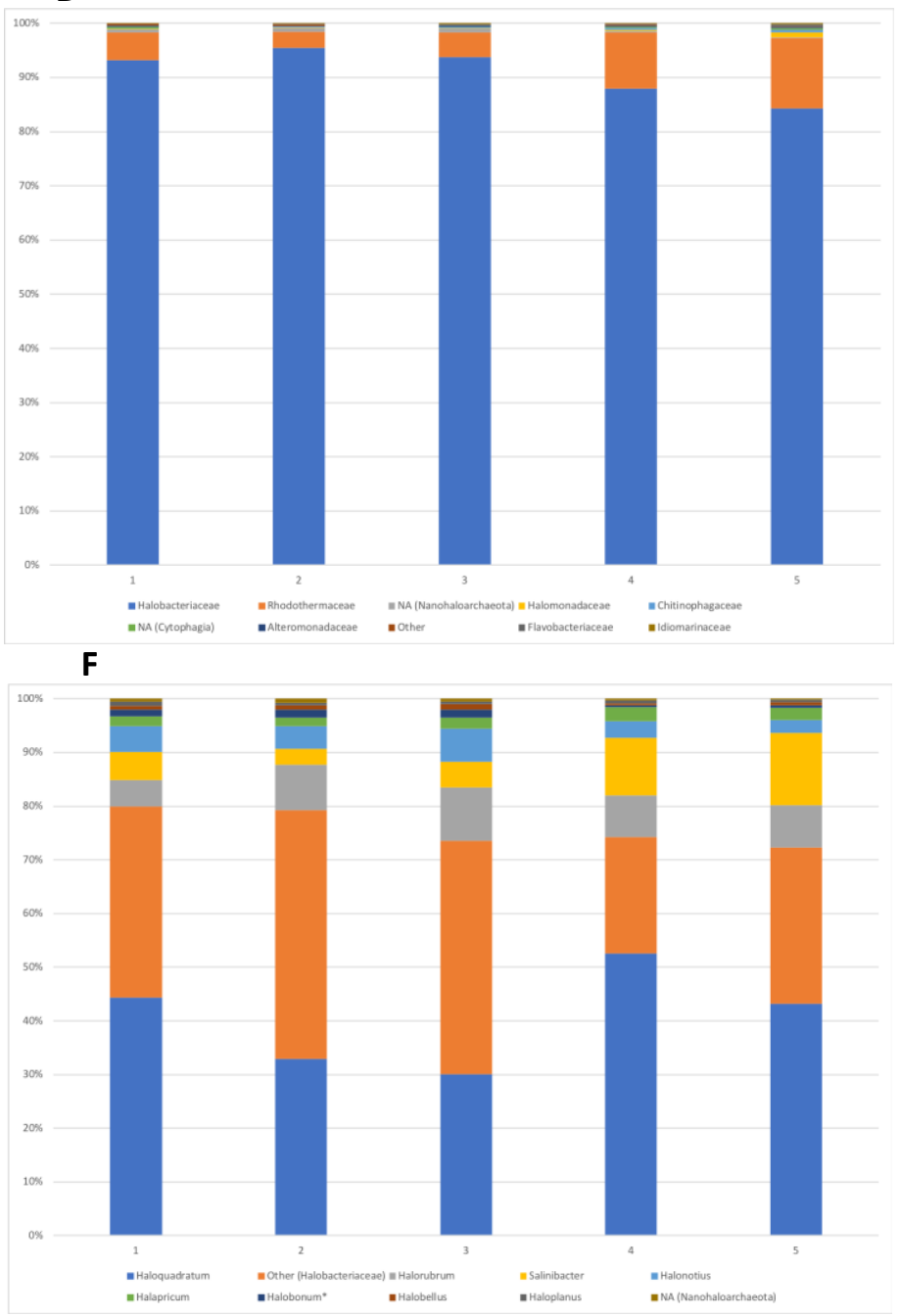

Şekil 2. 16S rDNA metabarkodlama sonuçlarına göre örneklerin rölatif mikrobiyal kompozisyonun (A ve B) filum düzeyinde, (C ve D) aile düzeyinde, (E ve F) cins düzeyinde gösterilmesi. A, C, E grafikleri Greengenes veri bankası ve B, D, F grafikleri ise Zymo Research veri bankası'ndan elde edilen karşılaştırma sonuçlarından yararlanılarak hazırlanmıştır. 
Örnekler fizikokimyasal parametreler göz önüne alınarak değerlendirildiğinde, tuzluluk açısından önemli bir fark olmamasına rağmen, sodyum ve klorür iyonları bakımından, en yüksek tuzluluğun ölçüldüğü örneklerde (2, 3 ve 4) arkeal OTU ların baskın olduğu belirlenmiştir ( $\geq 93)$. Görece daha düşük tuzluluğa sahip olan örnekte ise (5) ise çeşitliliğinin daha yüksek olduğu tespit edilmiştir (Şekil 3). Genel olarak, tüm örneklerde arkeler en dominant grup olarak belirlenmiştir ve belirlenen arkeal OTU'ların büyük çoğunluğu Euryarchaeota filumunda sınıflandırılan türlerle ilişkilidir. Tuz Gölü gibi tuzluluğun \%33 oranına yaklaştığı ortamlarda arkeler daha önce de baskın domeyn olarak tanımlanmıştır (Simachew ve ark., 2016). Tüm örneklerde en baskın görülen OTU ise Haloquadratum walsbyi 'e aittir. Bu bulgu, Mutlu ve arkadaşlarının 2008'de Tuz Gölü'nde gerçekleştirdikleri araştırmanın sonucuyla uyumludur. Ayrıca, Doğu Anadolu'da farklı tuzlalardan örnek alarak gerçekleştirilen çalışmada elde edilen sonuçlara göre, Euryarchaeota, Bacteroidetes, Proteobacteria ile Cyanobacteria üyelerinin hipersalin ortamlarda mikrobiyal kompozisyonun önemli bileşenleri olduğu ve Haloquadratum spp. ve Salinibacter spp.'nin en baskın cinsler olduğu yönündeki tespit de (Çınar ve Mutlu, 2016) bu çalışmanın sonuçlarıyla da uyumludur. $H$. walsbyi'nin farklı hipersalin ortamlardaki başarısının yüksek solar radyasyon ve çok yüksek magnezyum konsantrasyonlarını tolere edebilmesiyle ilişkili olduğu öne sürülmüştür (Bolhuis ve ark., 2006; Çınar ve Mutlu, 2016). Çalışmamızda tüm örneklerde en yüksek sıklıkta belirlenen bakteriyel OTU’ların ait olduğu Salinibacter cinsi ve diğer Bacteriodetes şubesi üyelerinin, orijinleri bakımından denizle ilişkili olan ya da daha genel anlamıyla kimyasal içeriği bakımından deniz suyuna benzerlik gösteren Tuz Gölü gibi thalassohaline ortamları uygun bir yaşam ortamı olarak benimsedikleri bilinmekt edir (Elevi Bardavit ve ark., 2007).

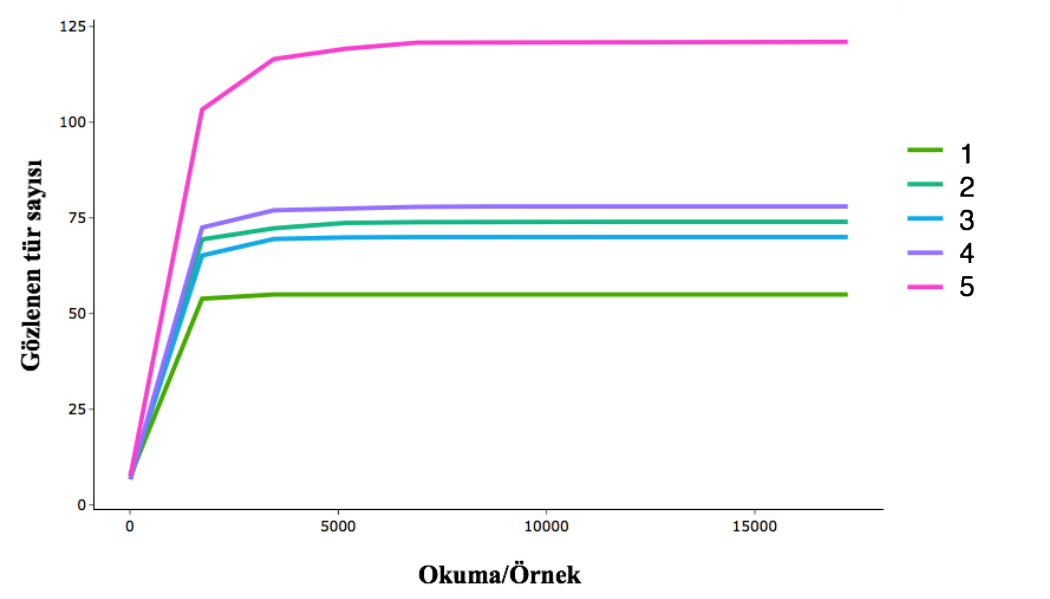

Şekil 3. 16S rDNA metabarkodlama verilerine göre örneklerin alfa çeşitlilik analizi sonuçları.

\subsubsection{S rDNA Dizileme}

Bu pilot çalışma kapsamında, Tuz Gölü’nden alınan 4 örnekte 18S rDNA dizileme başarılı sonuç vermiştir ve mikrobiyal kompozisyonun ökaryotik bileşenleri karakterize edilmiştir. 18S rDNA dizileme sonucu elde edilen ham okumalara veri kalitesini arttırmak için uygulanan filtreleme sonucunda, örnek başına ortalama 93764 yüksek kaliteli çift yönlü okuma elde edilmiştir. Örnek başına tespit edilen ortalama ökaryotik OTU sayısı 61 'dir (tanımlanan OTU sayısı 6-92 arasında değişmektedir). Tüm örneklerde bulunan ve çok bireyle temsil edilen OTU Chlorophyta'dan Dunaliella salina ile ilişkili olarak bulunmuştur. Bunu sırasıyla Saccharomycetales ordosuyla ilişkilendirilen bit OTU (Opisthokonta, Nucletmycea, Fungi) ve Navicula (SAR, Stramenopiles, Ochrophyta, Bacillariophyceae) cinsine ait bir OTU ile yine Bacillariophyceae ailesinden bir başka OTU izlemektedir. Opisthokonta, SAR, Amoebazoa, Cryptophyceae, Excavata ve Haptopyhta üst gruplarına ait OTU'lar da belirlenmiştir. Ancak, örneklerin her birinde çok sayıda okumanın ökaryot canlılara ait olduğu tespit edilmiş olmasına rağmen bu OTU'lar herhangi bir canlı ile ilişkilendirilememiştir, bu durumun veri bankalarında henüz ökaryotik türlerin prokaryotlar kadar çok temsil edilmemesinden kaynaklanabileceği düşünülmektedir (Şekil 4).

Örnekler fizikokimyasal parametreler göz önüne alınarak değerlendirildiğinde, tuzluluk ile tespit edilen ökaryotik mikrobiyal çeşitlilik açısından önemli bir fark belirlenememiştir. Bu çalışmada, tüm örneklerde en yaygın görülen ökaryotik OTU'nun Dunaliella salina ya ait olduğu tespit edilmiştir. D. salina daha önce hipersalin habitatların örneklendiği farklı çalışmalarda da baskın ökaryotik tür olarak rapor edilmiştir (Elevi Bardavit ve ark., 2007; Oren, 2005). 
A

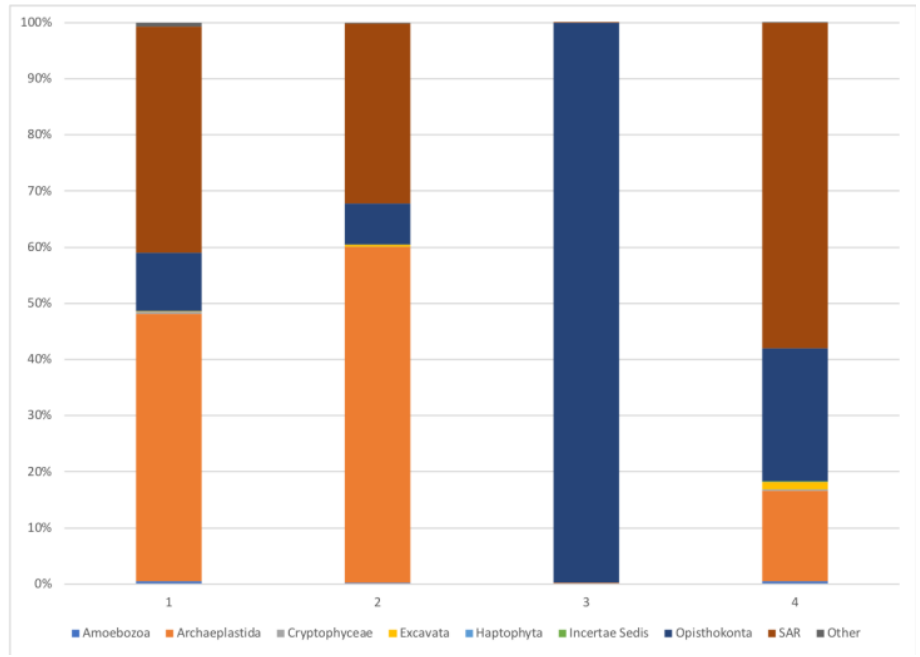

B

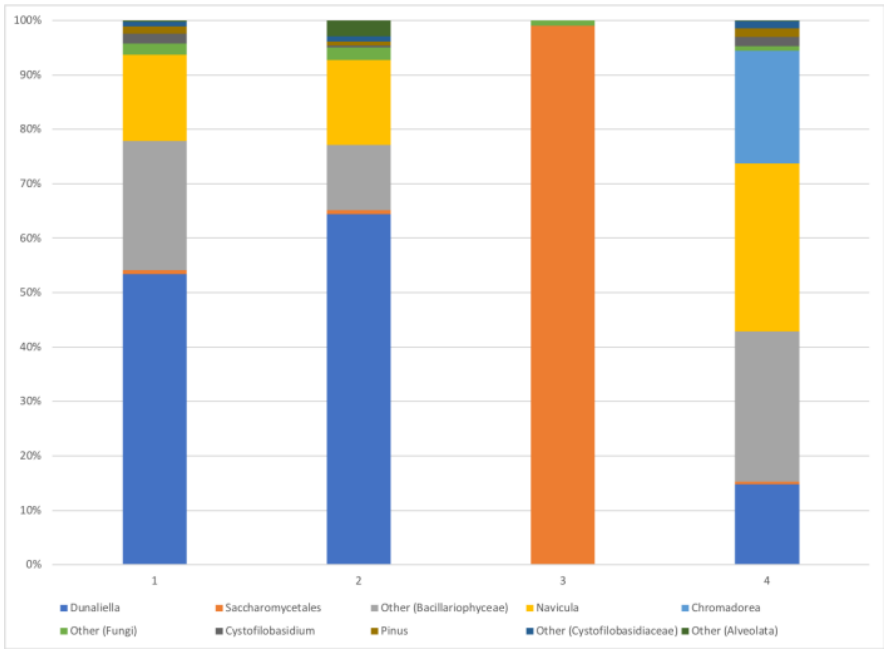

Şekil 4. 18S rDNA metabarkodlama sonuçlarına göre örneklerde rölatif mikrobiyal kompozisyonun (A) filum düzeyinde ve (B) cins düzeyinde gösterilmesi.

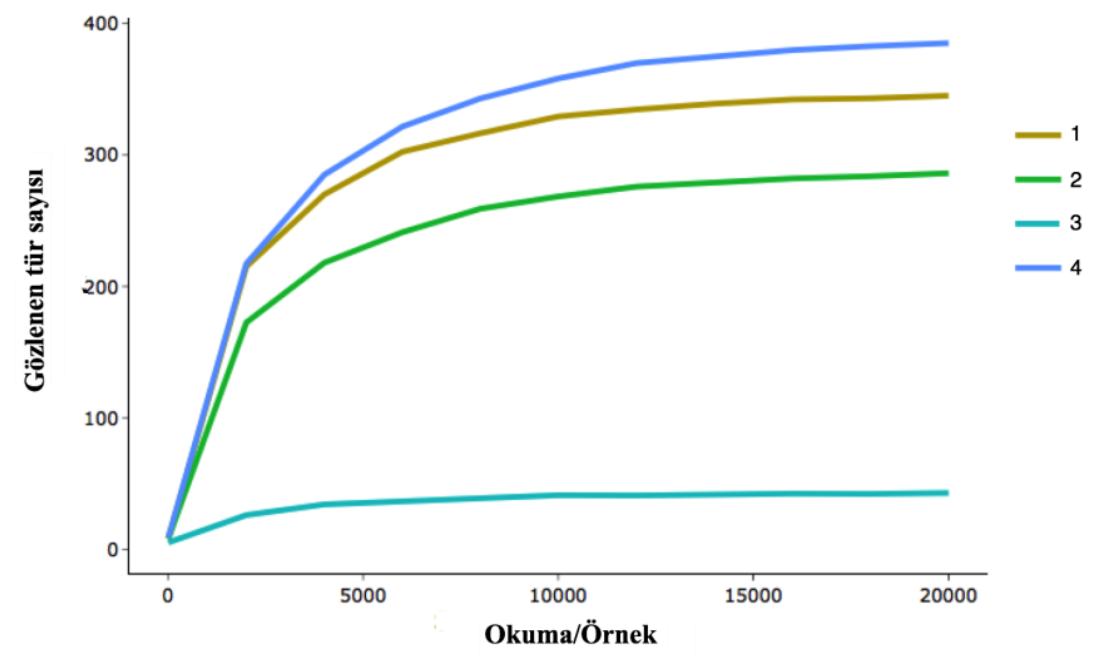

Şekil 5. 18S rDNA metabarkodlama verilerine göre örneklerin alfa çeşitlilik analizi sonuçları.

\section{Sonuç}

Doğal popülasyonların, özellikle de mikrobiyal komünitelerin karmaşıklığı ve çeşitliliği hakkındaki anlayışımız, çevresel bir örnekten elde edilen DNA'nın doğrudan dizilemesini başarabilen moleküler tekniklerin ortaya çıkmasıyla gelişmiştir. Mikrobiyal çeşitliliğin tespit edilmesinde en çok kullanılan yaklaşımlar olan metagenomik ve metabarkodlama, toprak, deniz gibi çevresel örnekler ya da insan vücudu gibi karmaşık toplulukların analizinde bir devrim yaratmıştır. Bu yöntemler, biyoçeşitlilik hakkında bilgi sağlamanın yanı sıra, organizmaların yaşam döngüleri ve bulundukları ekosistemdeki işlevleri ve hatta insan sağlığı ile ilişkili rolleri hakkında da fikir edinmemizi sağlamaktadır. Ek olarak, özellikle uç özelliklere sahip çevresel kaynaklardan elde edilen bilgiler filogenetik olarak yeni canlı türlerinin tanımlanmasına olanak sağlamaktadır (Ghai ve ark, 2011). Geçmişte, kültür temelli teknikler kullanılarak mikrobiyota hakkında önemli bilgiler elde edilmiştir, ancak kültürden bağımsız moleküler yaklaşımların kullanılmasıyla birlikte mikrobiyota bilgilerinin eksiklikler içerdiği ve hatta yanlış olabildiği görülmüştür (Fouts ve ark., 2012).

Bu çalışmada, kültürden bağımsız bir yöntem olan metabarkodlama yaklaşımı kullanılarak Tuz Gölü`nde seçilen bir pilot bölgeden alınan su örneklerinde mikrobiyal biyoçeşitliliğin ortaya konulması amaçlanmıştır. Metagenomik ve metabarkodlama yaklaşımları, daha önce farklı hipersalin ortamların mikrobiyal bileşimlerini araştırmak için kullanılmıştır (Ghai ve ark., 2011; Fernandez ve ark., 2014). 
Tuz Gölü'nde daha önce gerçekleştirilen benzer çalışmalarda kullanılan mikroskopi ve kültür tekniklerine dayanan geleneksel yöntemler, çevresel örneklerde mevcut olan mikrobiyal çeşitliliği tam olarak belirlemek için zaman zaman yetersiz kalabilmekt edir. Bu nedenle, önceki çalışmalarda Tuz Gölü mikrobiyal çeşitliliğinin moleküler karakterizasyonunun yalnızca geleneksel yöntemlerle tanımlanabilen halofiller ile sınırlı kalmış olabileceği öne sürülebilir. Ek olarak, Tuz Gölü ökaryotik mikroorganizmalarını değerlendiren bir çalışmanın literatürde yer almaması da bu pilot çalışmanın gerçekleştirilmesinin bir diğer önemli nedenidir.

Sonuç olarak, bu çalışmada, Türkiye'nin en önemli doğal alanlarıdan biri olan Tuz Gölü'nde seçilmiş bir bölgenin mikrobiyal kompozisyonun temel bileşenleri tanımlanmıştır. Analizi yapılan örneklerin her birinde mikrobiyom hakkında kapsamlı bir görüş elde edilmiștir. Ancak hızla değişen mikrobiyal komünite dinamikleri göz önüne alındığında, büyük bir ekolojik alan olan Tuz Gölü'nde sadece tek bir lokasyonun anlık mikrobiyal çeşitliliğinin belirlenmesi yetersizdir. Bu nedenle, gelecekteki çalışmalarda farklı mevsimlerde gölün farklı bölgelerinden örnekler alınarak Tuz Gölü mikrobiyotası analizlerinin detaylandırılması planlanmaktadır.

\section{Teşekkür}

Çalışmanın planlanması sırasındaki yardımcı ve eleştirel yorumları için Prof. Dr. Hatice Mergen, Doç. Dr. Sırma Çapar Dinçer ve Deniz Eyice'ye teşekkür ederim. Bu çalışma Hacettepe Üniversitesi Bilimsel Araştırma Projeleri Koordinasyon Birimi (FHD-2017-16050 numaralı proje) tarafından desteklenmiştir.

\section{Kaynakça}

Abdallah MB, Karray F, Mhiri N, Mei N, Quéméneur M, Cayol JL, et al. (2016). Prokaryotic diversity in a Tunisian hypersaline lake, Chott El Jerid. Extremophiles, 20, 125-138.

Abdelfattah A, Malacrinò A, Wisniewski M, Cacciola SO \& Schena L. (2017). Metabarcoding: a powerful tool to investigate microbial communities and shape future plant protection strategies. Biol Control, 120, 1-10.

Amann RI, Lin C, Key R, Montgomery L and Stahl DA. (1992). Diversity among Fibrobacter isolates: towards a phylogenetic classification. Syst Appl Microbiol, 15, 23-31.

Amaral-Zettler LA, McCliment EA, Ducklow HW, \& Huse SM. (2009). A method for studying protistan diversity using massively parallel sequencing of V9 hypervariable regions of small-subunit ribosomal RNA Genes. PLoS ONE, 4, e6372.

Birbir M, Sesal C. (2003). Extremely halophilic bacterial communities in Şereflikoçhisar Salt Lake in Turkey. Turk J Biol, 27, 7-22.

Bolhuis H, Palm P, Wende A, Falb M, Rampp M, Rodriguez-Valera F, Pfeiffer F, Oesterhelt D. (2006). The genome of the square archaeon Haloquadratum walsbyi: life at the limits of water activity. BMC Genomics, 7, 169.

Brown DS, Jarman SN, Symondson WO. (2012). Pyrosequencing of prey DNA in reptile faeces: analysis of earthworm consumption by slow worms. Mol Ecol Res, 12, 259-266.

Callahan BJ, McMurdie PJ, Rosen MJ, Han AW, Johnson AJA, Holmes S. (2016). DADA2: High resolutionsample inference from Illumina amplicon data. Nat Methods, 13, 581-583.

Caporaso JG, Kuczynski J, Stombaugh J, Bittinger K, Bushman FD, et al. (2010). QIIME allows analysis of high throughput community sequencing data. Nat Methods, 7, 335-336.

Caporaso JG, Lauber CL, Walters WA, Berg-Lyons D, Lozupone CA, Turnbaugh PJ, Noah Fierer N, \& Knight R. (2011). Global patterns of 16S rRNA diversity at a depth of millions of sequences per sample. Proc Natl Acad Sci USA, 108, 4516-4522.

Caporaso JG, Lauber C L, Walters W A, Berg-Lyons D, Huntley J, Fierer N, Owens SM, Betley J, Fraser L, Bauer M, Gormley N, Gilbert JA, Smith G, \& Knight R. (2012). Ultra-high-throughput microbial community analysis on the Illumina HiSeq and MiSeq platforms. ISME J, 6, 1621-1624.

Collins MD, Rodrigues U, Ash C, Aguirre M, Farrow JAE, Martinez-Murcia A, Phillips BA, Williams AM and Wallbanks S. (1991). Phylogenetic analysis of the genus Lactobacillus and related lactic acid bacteria as determined by reverse transcriptase sequencing of 16S rRNA. FEMS Microbiol Lett, 77, 5-12.

Çınar S, Mutlu MB. (2016). Comparative analysis of prokaryotic diversity in solar salterns in eastern Anatolia (Turkey). Exteremophiles, 20, 589-601.

DeSantis TZ, Hugenholtz P, Larsen N, Rojas M, Brodie EL, Keller K, et al. (2006). Greengenes, a chimera-checked 16S rRNA gene database and workbench compatible with ARB. Appl Environ Microbiol, 72, 5069-5072.

Edgar RC. (2013). UPARSE: Highly accurate OTU sequences from microbial amplicon reads. Nature Methods, 10, 996-998.

Elevi Bardavid R, Ionescu D, Oren A, Rainey FA, Hollen BJ, Bagaley DR, Small AM, McKay C. (2007). Selective enrichment, isolation and molecular detection of Salinibacter and related extremely halophilic Bacteria from hypersaline environments. Hydrobiologica, $576,3-13$.

Emerson JB, Thomas BC, Andrade K, Allen EE, Heidelberg KB, Banfield JF. (2012). Dynamic viral populations in hypersaline systems as revealed by metagenomic assembly. Appl. Environ. Microbiol, 78, 6309-6320.

Emerson JB, Andrade K, Thomas BC, Norman A, Allen EE, Heidelberg KB, Banfield JF. (2013). Virus-host and CRISPR dynamics in arkeler-dominated hypersaline Lake Tyrrell, Victoria, Australia. Archaea, 370871.

Fernandez AB, Ghai R, Martin-Cuadrado AB, Sanchez-Porro C, Rodriguez-Valera F, Ventosa A. (2014). Prokaryotic taxonomic and metabolic diversity of an intermediate salinity hypersaline habitat assessed by metagenomics. FEMS Microbiol Ecol, 88, 623-635.

Fouts DE, Szpakowski S, Purushe J, Torralba M, Waterman RC, et al. (2012). Next generation sequencing to define prokaryotic and fungal diversity in the bovine rumen. PLoS ONE, 7, e48289. 
Fox GE, Wisotzkey JD and Jurtshuk P. (1992). How close is close: 16S rRNA sequence identity may not be sufficient to guarantee species identity. Int J Syst Bacteriol, 42, 166-170.

Ghai R, Pašić L, Fernández AB, Martin-Cuadrado AB, Mizuno CM, McMahon KD, Papke RT, Stepanauskas R, Rodriguez-Brito B, Rohwer F, Sánchez-Porro C, Ventosa A, Rodríguez-Valera F. (2011). New abundant microbial groups in aquatic hypersaline environments. Scientific Reports, 1, 135.

Harris JK, Caporaso JG, Walker JJ, Spear JR, Gold NJ, Robertson CE, Hugenholtz P, Goodrich J, McDonald D, Knights D, Marshall P, Tufo H, Knight R, Pace NR. (2013). Phylogenetic stratigraphy in the Guerrero Negro hypersaline microbial mat. ISME J, 7, 50-60.

Hiiesalu I, Opik M, Metsis M, Lilje L, Davison J, et al. (2012). Plant species richness belowground: higher richness and new patterns revealed by next- generation sequencing. Mol Ecol, 21, 2004-2016.

Koday S. (1999). Tuz Gölü tuzlaları. Marmara Coğrafya Dergisi, 2, 128-149.

Kowalczyk R, Taberlet P, Coissac E, Valentini A, Mique C et al. (2011). Influence of management practices on large herbivore dietCase of European bison in Białowieza Primeval Forest (Poland). F Ecology and Management, 261, 821-828.

Martinez-Murcia AJ and Collins MD. A phylogenetic analysis of the genus Leuconostoc based on reverse transcriptase sequencing of 16 S rRNA. FEMS Microbiol Lett 1990; 70: 73-83.

Martinez-Murcia AJ, Benlloch S and Collins MD. (1992). Phylogenetic interrelationships of members of the genera Aeromonas and Pleisiomonas as determined by $16 \mathrm{~S}$ ribosomal DNA sequencing: lack of congruence with results of DNA-DNA hybridizations. Int $J$ Syst Bacteriol, 42, 412-421.

Mutlu MB. (2006). Tuz Gölü bakterilerinin karaterizasyonu ve mevsimsel dagilimi (doktora tezi). Anbadolu Universitesi, Eskisehir, Turkiye.

Mutlu MB, Martinez-Garcia M, Santos F, Pena A, Guven K \& Anton J. (2008). Prokaryotic diversity in Tuz Lake, a hypersaline environment in inland Turkey. FEMS Microbiol Ecol, 65, 474-483.

Oren A. (2005). A hundred years of Dunaliella research: 1905-2005. Saline Systems, 1, 2.

Oren A. (2014). Halophilic arkeler on earth and in space: growth and survival under extreme conditions. Philos Trans R Soc A, 372, 20140194.

Pace NR. (1997). A molecular view of microbial diversity and the biosphere. Science, 276, 734-740.

Parada AE, Needham DM, \& Fuhrman JA. (2016). Every base matters: assessing small subunit rRNA primers for marine microbiomes with mock communities, time series and global field samples. Environ Microbiol, 18, 1403-1414.

Pavan-Kumar A, Gireesh-Babu P and Lakra WS. (2015). DNA Metabarcoding: A new approach for rapid biodiversity assessment. $J$ Cell Sci Mol Biol, 2, 111.

Pike LJ, Viciani E, Kumar N. (2018). Microbial diversity knows no borders. Nat Rev Microbiol, 16, 66.

Porazinska DL, Giblin-Davis RM, Esquivel A, Powers TO, Sung W, et al. (2010). Ecometagenetics confirms high tropical nematode diversity. Mol Ecol, 19, 5521-5530.

Ramette A. (2009). Quantitative community fingerprinting methods for estimating the abundance of operational taxonomic units in natural microbial communities. Appl Environ Microbiol, 75, 2495-2505.

Raye G, Miquel C, Coissac E, Redjadj C, Loison A, et al. (2011). New insights on diet variability revealed by DNA barcoding and highthroughput pyrosequencing: chamois diet in autumn as a case study. Eco Res, 26, 265- 276.

Simachew A, Lanzén A, Gessesse A, Øvreås L. (2016). Prokaryotic community diversity along an increasing salt gradient in a soda ash concentration pond. Microb Ecol, 71, 326-338.

Sogin ML, Morrison HG, Huber JA, Welch DM, Huse SM, et al. (2006). Microbial diversity in the deep sea and the underexplored "rare biosphere." Proc Natl Acad Sci USA, 103, 12115-12120.

Tazi L, Breakwell DP, Harker AR, Crandall KA. (2014). Life in extreme environments: microbial diversity in Great Salt Lake, Utah. Extremophiles, 18, 525-535.

Tindall BJ, Rossello-Mora R, Busse, H-J, Ludwig W, Kampfer P. (2010). Notes on the characterization of prokaryote strains for taxonomic purposes. Int J Sys Evo Microbiol, 60, 249-266.

Ventosa A, Fernández AB, León MJ, Sánchez-Porro C, Rodriguez-Valera F. (2014). The Santa Pola saltern as a model for studying the microbiota of hypersaline environments. Extremophiles, 18, 811-824.

Walters W, Hyde ER, Berg-Lyons D, Ackermann G, Humphrey G, Parada A, Gilbert JA, Jansson JK, Caporaso JG, Fuhrman JA, Apprill A, \& Knight R. (2016). Improved bacterial 16S rRNA gene (V4 and V4-5) and fungal internal transcribed spacer marker gene primers for microbial community surveys. mSystems, 1: e00009-15. 